\title{
Bone mineral density changes in patients with rheumatoid arthritis
}

\begin{abstract}
Ashna Swara Saleh *
Shwan K. Media **

Abstract

Background and objective: Bone loss regarded as a major health concern which is thought to be associated with a number of chronic illnesses including rheumatoid arthritis. This study was designed to determine the frequency of low bone mass as well as the influence of disease duration on bone mass in the patients with rheumatoid arthritis.

Methods: Sixty patients with rheumatoid arthritis who were visiting Rizgary Teaching Hospital in Erbil from April 2015 to March 2016were included in a cross-sectional study. Bone mineral density was measured using dual energy X-ray absorptiometry.

Results: There was increased frequency of bone loss in patients with rheumatoid arthritis. There was a positive association between bone mineral density of the spine and femoral neck with disease activity measured by disease activity score and disease activity index $(P<0.05)$. There was a significant association between bone mineral density and disease duration.

Conclusion: Significant proportions of patients with rheumatoid arthritis have osteoporosis at the femoral neck and lumber spine, and disease duration longer than five years is associated with a significant increase in bone loss.
\end{abstract}

Keywords: Rheumatoid arthritis; Bone loss; Bone densitometry

\section{Introduction}

Rheumatoid arthritis (RA) is a chronic systemic autoimmune inflammatory disease that affects all ethnic groups throughout the world ${ }^{1}$ characterized by symmetric erosive synovitis. ${ }^{2}$ Female are 2.5 times more likely to be affected than male. ${ }^{3}$ Rheumatoid arthritis is associated with periarticular bone loss adjacent to inflamed joints and generalized osteoporosis, leading to increased risk of fractures in both the appendicular and axial skeleton. ${ }^{4}$ The chronic synovial inflammation in RA can promote osteoclast genesis, leading directly to both focal and generalized bone loss and increased risk of fractures. In addition, many indirect factors associated with inflammatory arthritis contribute to risk of osteoporosis including immobility, weight loss, and use of medications known to promote bone loss such as glucocorticoids and disease modifying agents. ${ }^{5}$ Bone mass in RA appears to be adversely affected by functional impairment and active inflammation, especially in early course of disease. ${ }^{5}$ Osteoporosis is a disease defined by low bone density and deterioration of micro architectures, which reduces bone strength and increase fracture risk. The prevalence of osteoporosis increase markedly with increasing age, fractures related to osteoporosis are a major public health problem in all developed countries, affection up to $30 \%$ of women and $12 \%$ of men at some time of their life. ${ }^{1}$ The threshold for establishing a diagnosis of osteoporosis will be based on the world health organization (WHO) definition; bone mineral density (BMD) is measured by using dual energy $X$-ray absorptiometry (DEXA) at proximal femur and lumbar spine. ${ }^{6}$ Osteoporosis is an extra-articular

* Department of Rheumatology and Medical Rehabilitation, Rizgary Teaching Hospital, Erbil, I raq.

** Department of I nternal Medicine, College of Medicine, Hawler Medical University, Erbil, I raq. 
complication of rheumatoid arthritis. Decrease bone mineral density (BMD) plus an Increase of both hip and vertebral fractures in patients with RA compared with patients without RA has been demonstrated in several studies. ${ }^{7,8}$ The Disease Activity Score 28 (DAS28) is a major scoring system for evaluating disease activity of RA. The initial development of DAS was reported by van der Heijde et al. in 1990 and 1992, and then DAS was modified by a group of investigators from the Netherlands. ${ }^{9}$ The use of DAS28 is officially recommended by the European League against Rheumatism (EULAR) for evaluating disease activity and the improvement in disease activity in clinical trials and also in daily clinical practice. DAS28 is calculated according to the formula that is composed of the number of tender joints and swollen joints, patient's global assessment of disease activity on a visual analogue scale (VAS), and erythrocyte sedimentation rate (ESR), or C-reactive protein (CRP). ${ }^{9}$ In clinical practice, CRP and ESR are used in monitoring disease activity and response to the treatment. CRP is one of the best indicators of the acute phase response to inflammation, because it may increase to 1,000 fold during an acute phase reaction. Increased values are found in chronic and acute inflammation. ${ }^{10}$ This study was designed to assess the frequency of bone loss with RA in patients living in Erbil city as no similar studies has been conducted before in Kurdistan region.

\section{Methods}

This cross-sectional study was carried out in the Rheumatology and Medical Rehabilitation Department of Rizgary Teaching Hospital in Erbil City from April 2015 to March 2016. Sixty patients who fulfilled EULAR-ACR-2010 and ACR 1987 criteria for RA were chosen by convenience method of sampling. The exclusion criteria included those patients who had metabolic and endocrine disease (hypothyroidism and hyperthyroidism), other inflammatory diseases like systemic lupus erythematosis, inflammatory bowel diseases, patients who had BMI less than 19 , patients less than 16 years and above 55 years of age, patients with chronic alcoholism, who were pregnant and those who were on certain drugs such as cyclosporine, prednisolone $>5 \mathrm{mg}$, thyroxin, heparin, and anticonvulsants. Data were collected and recorded on a specially designed questionnaire after getting verbal consent from the patients. Laboratory investigations were done to estimate ESR, latex test. Bone mineral density was measured for all patients using DEXA at proximal femur and lumbar spine to diagnose osteoporosis according to world health organization definition. T-score = 1 standard deviation (SD) consider normal, T-score between- 1 to $>-2.5$ consider osteopenia T-score $\leq-2.5$ consider osteoporosis. The activity of disease was assessed by DAS28 and CDAI parameters. Based on DAS28 patients were graded as in remission $<2.6$, low active <3.2, moderate 3.2-5.1 and highly active $>5.1$ and for CDAl were entitled into in remission $<2.8$, low active $<10$, moderate 10-22 and highly active $>22$. The influence of disease duration on BMD was assessed by comparison of the BMD values between patients with disease duration of less than two years with those with disease duration of 2-5 years as well as with patients with a disease duration longer than five years. Drug therapy was noted. The data were managed by Excel using Chi-square test. A $P$ value less than 0.05 was considered statistically significant. The study protocols of the original research projects and the current study were approved by the Research Ethics Committee at the College of Medicine of Hawler Medical University.

\section{Results}

A total of 60 participants joined the study; $93.3 \%$ of them were female and $6.7 \%$ were male. The female to male ratio was $14: 1$. The mean age \pm SD were $42.2 \pm 9.3$ years, the age of participants was ranging from 24 
to 55 years. Most of the study participants were female, non-smoker, having RA for less than two years, with sun-exposure of less than 20 minutes and walking for less than half an hour per day. Most of the participants had negative rheumatoid factor and family history of RA;

Table 1: Descriptive data of participants.

\begin{tabular}{|c|c|c|c|}
\hline Variables & Categories & No. & $\%$ \\
\hline \multirow[t]{2}{*}{ Gender } & Male & 4 & 6.7 \\
\hline & Female & 56 & 93.3 \\
\hline \multirow[t]{3}{*}{ Disease duration } & $<2$ years & 27 & 45 \\
\hline & $2-5$ years & 12 & 20 \\
\hline & $>5$ years & 21 & 35 \\
\hline \multirow[t]{2}{*}{ Smoking } & Yes & 7 & 11.7 \\
\hline & No & 53 & 88.3 \\
\hline \multirow[t]{2}{*}{ Sun exposure } & $\geq 20 \min$ & 20 & 33.3 \\
\hline & $<20 \min$ & 40 & 66.7 \\
\hline \multirow[t]{2}{*}{ Walking } & $\geq 30 \mathrm{~min}$ & 14 & 23.3 \\
\hline & $<30 \min$ & 46 & 76.7 \\
\hline \multirow[t]{5}{*}{ Current medications } & Steroids & 4 & 6.7 \\
\hline & DEMARD & 13 & 21.7 \\
\hline & DEMARD + Biologics & 19 & 31.7 \\
\hline & DEMARD + Steroids & 23 & 38.3 \\
\hline & None & 1 & 1.7 \\
\hline \multirow[t]{2}{*}{ Compliance } & Regular & 41 & 68.3 \\
\hline & Irregular & 19 & 31.7 \\
\hline \multirow[t]{2}{*}{ Family history } & Positive & 26 & 43.3 \\
\hline & Negative & 34 & 56.7 \\
\hline \multirow[t]{2}{*}{ Morning stiffness } & $<1$ hour & 46 & 76.7 \\
\hline & $\geq 1$ hour & 14 & 23.3 \\
\hline \multirow[t]{2}{*}{ Rheumatoid factor } & Positive & 28 & 46.7 \\
\hline & Negative & 32 & 53.3 \\
\hline \multirow[t]{4}{*}{ DAS-28 } & Remission & 12 & 20 \\
\hline & Low & 5 & 8.3 \\
\hline & Moderate & 12 & 20 \\
\hline & High & 31 & 51.7 \\
\hline \multirow[t]{4}{*}{ CDAI } & Remission & 28 & 46.7 \\
\hline & Low & 10 & 16.7 \\
\hline & Moderate & 6 & 10 \\
\hline & High & 16 & 26.7 \\
\hline
\end{tabular}

they were receiving DEMARD and steroids as the first treatment option, with regular compliance, morning stiffness of less than one hour associated with high DAS 28 levels and remission CDAl results (Table 1). 
There was a significant statistical association between BMD spine and duration of disease, CDAI and DAS28. Totally 8 cases $(13.3 \%)$ had osteoporosis in lumber spine, while 13 cases (21.6) had osteopenia. Most of the patients with normal BMD spine had the disease for less than two years in contrast to patients with osteopenia and osteoporosis who had the disease for more than five years. The large percentage of participants with normal BMD spine were in remission phase according to CDAI and DAS 28 results while most of osteopenia and osteoporosis cases had moderate or high CDAl and DAS levels. There was a non-significant statistical relationship between BMD spine and gender and smoking. The majority of participants were non-smoker and female (Table 2).

Table 2: Association between BMD Spine and different measures.

\begin{tabular}{|c|c|c|c|c|c|}
\hline \multirow[b]{2}{*}{ Measure } & \multirow[b]{2}{*}{ Category } & \multicolumn{3}{|c|}{ BMD Spine } & \multirow[b]{2}{*}{$P$ value } \\
\hline & & $\begin{array}{l}\text { Normal } \\
\text { No. (\%) }\end{array}$ & $\begin{array}{c}\text { Osteopenia } \\
\text { No. (\%) }\end{array}$ & $\begin{array}{l}\text { Osteoporosis } \\
\text { No. (\%) }\end{array}$ & \\
\hline \multirow[t]{2}{*}{ Gender } & Male & $2(50 \%)$ & $1(25 \%)$ & $1(25 \%)$ & \multirow[b]{2}{*}{0.73} \\
\hline & Female & $37(66.1 \%)$ & $12(21.4 \%)$ & $7(12.5 \%)$ & \\
\hline \multirow[t]{2}{*}{ Smoking } & Yes & $4(57.1 \%)$ & $0(28.6 \%)$ & $3(14.3 \%)$ & \multirow[b]{2}{*}{0.88} \\
\hline & No & $35(66 \%)$ & $11(20.8 \%)$ & $7(13.2 \%)$ & \\
\hline \multirow[t]{4}{*}{ CDAI } & Remission & $22(78.6 \%)$ & $3(10.7 \%)$ & $3(10.7 \%)$ & \multirow{5}{*}{0.01} \\
\hline & Low & $7(70 \%)$ & $2(20 \%)$ & $1(10 \%)$ & \\
\hline & Moderate & $4(66.7 \%)$ & $0(0 \%)$ & $2(33.3 \%)$ & \\
\hline & High & $6(37.5 \%)$ & $8(50 \%)$ & $2(12.5 \%)$ & \\
\hline \multirow[t]{4}{*}{ DAS 28} & Remission & $12(100 \%)$ & $0(0 \%)$ & $0(0 \%)$ & \\
\hline & Low & $1(20 \%)$ & $2(40 \%)$ & $2(40 \%)$ & \multirow{3}{*}{0.01} \\
\hline & Moderate & $10(83.3 \%)$ & $2(16.7 \%)$ & $0(0 \%)$ & \\
\hline & High & $16(51.6 \%)$ & $9(29 \%)$ & $6(19.4 \%)$ & \\
\hline \multirow[t]{3}{*}{ Duration } & $<2$ years & $26(96.3 \%)$ & $0(0 \%)$ & $1(3.7 \%)$ & \multirow{3}{*}{0.001} \\
\hline & 2-5 years & $6(50 \%)$ & $4(33.3 \%)$ & $2(16.7 \%)$ & \\
\hline & $>5$ years & $7(33.3 \%)$ & $9(42.9 \%)$ & $5(23.8 \%)$ & \\
\hline
\end{tabular}


Except for smoking, there was a significant statistical association between BMD of the femoral neck and all associated features. The frequency of OP and osteopenia in $\mathrm{FN}$ (femoral neck) were 23.3\% (14 cases), $28.3 \%$ (17cases) respectively. Most of the patients with normal BMD the disease for less than two years in reverse to patients with osteoporosis who had the disease for more than five years. The largest proportion of participants with normal BMD spine were in remission phase according to CDAI results while most of osteopenia and osteoporosis cases had moderate or high CDAl levels. Approximately $70 \%$ of osteopenia and osteoporosis conditions had high DAS readings in contrast to only $30 \%$ of normal BMD participants (Table 3 ).

Table 3: Association between BMD Femoral neck and different measures.

\begin{tabular}{|c|c|c|c|c|c|}
\hline \multirow[b]{2}{*}{ Measure } & \multirow[b]{2}{*}{ Category } & \multicolumn{3}{|c|}{ BMD Femoral Neck } & \multirow[b]{2}{*}{$P$ value } \\
\hline & & $\begin{array}{l}\text { Normal } \\
\text { No.(\%) }\end{array}$ & $\begin{array}{l}\text { Osteopenia } \\
\text { No. (\%) }\end{array}$ & $\begin{array}{c}\text { Osteoporosis } \\
\text { No. (\%) }\end{array}$ & \\
\hline \multirow[t]{2}{*}{ Gender } & Male & $0(0 \%)$ & $1(25 \%)$ & $3(75 \%)$ & \multirow[b]{2}{*}{0.03} \\
\hline & Female & $29(51.8)$ & $16(28.6 \%)$ & $11(19.6 \%)$ & \\
\hline \multirow[t]{2}{*}{ Smoking } & Yes & $4(57.1 \%)$ & $0(0 \%)$ & $3(42.9 \%)$ & \multirow[b]{2}{*}{0.16} \\
\hline & No & $25(47.2 \%)$ & $17(32.1 \%)$ & $11(20.8 \%)$ & \\
\hline \multirow[t]{4}{*}{ CDAI } & Remission & $20(71.4 \%)$ & $3(10.7 \%)$ & $5(17.9 \%)$ & \multirow{4}{*}{0.03} \\
\hline & Low & $4(40 \%)$ & $4(40 \%)$ & $2(20 \%)$ & \\
\hline & Moderate & $1(16.7 \%)$ & $3(50 \%)$ & $2(33.3 \%)$ & \\
\hline & High & $4(25 \%)$ & $7(43.8 \%)$ & $5(31.3 \%)$ & \\
\hline \multirow[t]{4}{*}{ DAS 28} & Remission & $8(66.7 \%)$ & $3(25 \%)$ & $1(8.3 \%)$ & \multirow{4}{*}{0.03} \\
\hline & Low & $2(40 \%)$ & $1(20 \%)$ & $2(40 \%)$ & \\
\hline & Moderate & $10(83.3 \%)$ & $1(8.3 \%)$ & $1(8.3 \%)$ & \\
\hline & High & $9(29 \%)$ & $12(38.7 \%)$ & $10(32.3 \%)$ & \\
\hline \multirow[t]{3}{*}{ Duration } & $<2$ years & $19(70.4 \%)$ & $7(25.9 \%)$ & $1(3.7 \%)$ & \multirow{3}{*}{0.001} \\
\hline & $2-5$ years & $5(41.7 \%)$ & $5(41.7 \%)$ & $2(16.7 \%)$ & \\
\hline & $>5$ years & $5(23.8 \%)$ & $5(23.8 \%)$ & $11(52.4 \%)$ & \\
\hline \multirow[t]{3}{*}{ BMD Spine } & Normal & $26(66.7 \%)$ & $10(25.6 \%)$ & $3(7.7 \%)$ & \multirow{3}{*}{0.001} \\
\hline & Osteopenia & $2(15.4 \%)$ & $5(38.4 \%)$ & $6(46.2 \%)$ & \\
\hline & Osteoporosis & $1(12.5 \%)$ & $2(25 \%)$ & $5(62.5 \%)$ & \\
\hline
\end{tabular}




\section{Discussion}

Osteoporosis (OP) has frequently been described in patients with RA and longitudinal studies have documented increased rate of bone loss in RA patients. $^{12,13}$ Hence we investigated prospectively the occurrence of osteoporosis and bone loss in RA patients and its association with disease activity. Furthermore, we estimated BMD in relation to disease duration. Our results show that osteoporosis occurred in $23.3 \%$ and $13.3 \%$ in the femoral neck and spine, respectively. This finding is more than Haungeberg et al., in a study of RA patient aged 20-70 years with a mean disease duration of 13 years, found OP at FN and LS in $14.7 \%$ and $16.8 \%$ of cases, respectively ${ }^{14}$ Our finding is less than that found in the study done in Iran in which $40.4 \%$ of cases had OP. ${ }^{15}$ In that study, the frequency of OP at the $\mathrm{FN}$ and LS were $34.9 \%$ and $25 \%$, respectively. This difference could be due to life- style, treatment option, lack of regular exercise and sun exposure. Additionally, in most other similar studies the prevalence of OP in RA has been higher than expected. A study in a cohort of general Chinese men has shown a significant association between RA and OP: the men with RA had a significant higher preva-lence of OP $(21.62 \%$ in RA group vs8.36\% in the non-RA group, $P=0.005) .{ }^{16}$ Our findings were consistent with other studies reported that $\mathrm{RA}$ was associated with $\mathrm{OP}$, a previous study has shown that there is a higher prevalence of OP in a group of Korean female RA patients (22.1\%) compared with the healthy control group $(11.4 \%) .^{17}$ Similarly, cohort study of 394 female patients with RA compared to control also revealed doubled preva-lence of OP. ${ }^{18}$ A study focusing on young patients with RA. ${ }^{19,20}$ In our study, we found that patients diagnosed with RA had significantly reduced bone mass

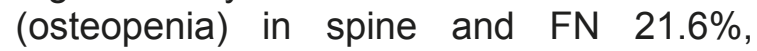
$28.3 \%$ respectively, this is close to Haungeberg et al., In a study of RA patient aged 20-70 years with a mean disease duration of 13 years, found the prevalence of reduced bone mass was $27.6 \%$ at $\mathrm{FN}$, and $31.6 \%$ at LS. ${ }^{14}$ The etiology of reduced bone mass in RA is multifactorial, including lifestyle risk factors and disease-related determinants. Persistently high levels of inflammation, low levels of physical activity and use of corticosteroids are associated with increased risk of bone loss. 12, 13,21-26 Our study also shows a positive association between BMD changes in RA patients and disease activity indicating higher DAS28 and CDAI in osteopenia and osteoporosis cases. This is in agreement with another study that has evaluated BMD and disease activity in RA patients as done in Birmingham 1996. Our finding did not match with the study done in Cairo, Egypt $2011^{27}$ which state that BMD changes do occur in patients with early RA, and are not necessarily correlated with disease activity (DAS-28). It is important to mention that disease duration of more than five years is associated with bone loss in particular at FN regardless of treatment. Most of the patients with normal BMD of spine and FN had disease duration for less than two years in reverse to patients with osteoporosis who had the disease for more than five years. This was matched with other study done in Iran $2005 .^{28}$ Finally, we found that there was statistically significant difference between BMD FN and spine, OP were more frequent in $F N$ it could be ascribed to osteoarthritis of the spine (osteoarthritis affect spine earlier than FN, in turn, lead to false increase of BMD), atherosclerosis of the aorta, and vertebral deformities, which increase the measured BMD and thus obscure a possible relation between potential predictors and 'true' BMD. $^{29}$ The same mechanism might explain the lower percentage of variance explained by the final model of spine BMD compared with hip BMD. Because of the difficult interpretation of a spine BMD measurement, recent recommendations prefer the measurement of BMD in the hip to other sites. ${ }^{30}$ There were some weak points in our study, it was a prospective 
cross-sectional study, and the sample size was relatively small. Furthermore, the selection of cases was not through random sampling, and certainly, there was selection bias. Thus more study is required to know the exact pathophysiology of bone loss in RA patient.

\section{Conclusion}

The results of this study indicate that a significant proportion of patients with RA have OP at the FN and LS, and disease duration longer than five years is associated with a significant increase in bone loss. Further longitudinal studies are required to know the exact pathophysiology of bone loss in RA patients. More interventional studies are required to investigate treatment option to prevent OP in RA patients.

\section{Conflicts of interest}

The authors report no conflicts of interest.

\section{References}

1. Doherty $M$, Lanyon $P$, Ralston $S H$. Rheumatoid arthritis. In: Boon NA; College NR; Walker BR; Hunter JAA (editors). Davidson's principles and practice of medicine, $20^{\text {th }}$ ed. New York: Churchill Livingstone; 2006. P.1101-6.

2. Taysi S, Polat F, Gul M, Sari RA, Bakan E. lipid peroxidation, some extracellar antioxidants and antioxidant enzymes in serum of patients with rheumatoid arthritis. Rheumatollnt 2002;21:200-4.

3. Heimick CG, Flson DT, Lawrence RC .National Arthritis Data, work group (Jan.2008)."Estimate of the prevalence of arthritis and other rheumatic conditions in the US. part I . Arthritis Rheumatism 58(1):15-25.

4. Tehlirian CV, Bathon JM. Clinical and laboratory manifestations.IN: Klippel $\mathrm{JH}$, Stone $\mathrm{JH}$, White $\mathrm{PH}$. Primer on the rheumatic diseases. New York: Springer Science \& Business Media; 2008. P.11421.

5. Aizer J, Reed G, Onofrie A, Harrisson MJ. Predictors of density testing in patients with rheumatoid arthritis. Rheumatol Int 2009; 29:897905.

6. Richards JS, Peng J, Amdur RI. Dual energy x-ray absorptiometry and rheumatoid arthritis. J ClinDensitom 2009; 12:434-40.

7. Spector TD, Hall GM, McCloskey EV, Kanis JA. Risk of vertebral fracture in women with rheumatoid arthritis. BMJ 1993;306:558.

8. Huusko TM, KarppiP,Avikainen H, Sulkava R. Threefold increase risk of hip fractures with rheumatoid arthritis incentralfinland. Ann Rheum Dis $2001 ; 60: 521-2$.

9. Van Leeuwen MA, van Rijswijk $M H$, van der Heijde DM, TeMeerman GJ, van Riel PL, Houtman PM, et al. The acute-phase response in relation to radiographic progression in early rheumatoid arthritis: a prospective study during the first three years of the disease. $\mathrm{Br} J$ Rheumatol 1993; 32(Suppl 3):9-13.

10. Tishler M, Caspi D, Yaron M. C - Reactive protein level in patients with rheumatoid arthritis, the impact of therapy. Clinical Rheumatol 1985;4 (3):321-4.

11. Simpson DS. Methodological and reporting consideration. In: Fordham JN. Manual of bone densitometry measurement.London: Springer; 2000. P. 37-54.

12. Shenstone BD, Mahmoud A, Woodward R, ElvinsD,Palmer R, Ring EF, Bhalla AK. Longitudinal bone mineral density changes in early rheumatoid arthritis. $\mathrm{Br} \mathrm{J}$ Rheumatol 1994; 33(6):541-5.

13. Kroger H, Honkanen R, Saarikoski S, Alhava E. Decreased axial bone mineral density in perimenopausal women with rheumatoid arthritis-a population based study. Ann Rheum Dis 1994; 53(1):18-23.

14. Haugeberg G, Orstavik RE, Uhlig T, Falch JA, Halse JI, Kvien TK. Bone loss in patients with rheumatoid arthritis: results from a population-based cohort of 366 patients followed up for two years. Arthritis Rheum 2002;46(7):1720 $-8$.

15. Mula K. A study of the bone density of rheumatoid arthritis patients in Khozestan province]. Journal of Shahid Sadoghi University of medical sciences and health services 2002; 3: 8-12.

16. Hui-Hong Piao, Ke-Qin Zhang, Zi-Hui Tang. Association between rheumatoid arthritics and osteoporosis among Chinese men, a community based study. Int J ClinExp Med 2015;8(9):165928.

17. Lee SG, Park YE, Park SH, Kim TK, Choi HJ, Lee SJ, et al. Increased frequency of osteoporosis and BMD below the expected range for age among South Korean women with rheumatoid arthritis. Int J Rheum Dis 2012; 15 : 289-96.

18. Haugeberg G, Uhlig T, Falch JA, Halse JI, Kvien TK. Bone mineral density and frequency of os-teoporosis in female patients with rheumatoid arthritis: results from 394 patients in the Oslo County Rheumatoid Arthritis register. Arthritis Rheum 2000; 43: 522-30.

19. Moon SJ, Ahn IE, Kwok SK, Park KS, Min JK, Park $\mathrm{SH}$, et al. Periarticular osteopo-rosis is a prominent feature in early rheuma-toid arthritis: estimation using shaft to periar-ticular bone mineral density ratio. J Korean Med Sci 2013; 28: 287-94. 
20. Deal C. Bone loss in rheumatoid arthritis: sys-temic, periarticular, and focal. CurrRheumatol Rep 2012; 14: 231-7.

21. Lane NE, Pressman AR, Star VL, Cummings SR, Nevitt MC. Rheumatoid arthritis and bone mineral density in elderly women. The Study of Osteoporotic Fractures Research Group. J Bone Miner Res 1995; 10(2):257- 63.

22. Dunne CA, Moran CJ, Thompson PW. The effect of regular intramuscular corticosteroid therapy on bone mineral density in rheumatoid patients. Scand J Rheumatol 1995; 24(1):48-9.

23. Buckley LM, Leib ES, Cartularo KS, Vacek PM, Cooper SM. Effects of low dose corticosteroids on the bone mineral density of patients with rheumatoid arthritis. J Rheumatol 1995; 22 (6):1055-9.

24. Devlin J, Lilley J, Gough A, Huissoon A, Holder R, Reece R, et al. Clinical associations of dual-energy X-ray absorptiometry measurement of hand bone mass in rheumatoid arthritis. $\mathrm{Br} \mathrm{J}$ Rheumatol 1996; 35(12):1256-62.

25. Cortet B, Flipo RM, Blanckaert F, Duquesnoy B, Marchandise $X$, Delcambre $B$. Evaluation of bone mineral density in patients with rheumatoid arthritis. Influence of disease activity and glucocorticoid therapy. Rev RhumEngl Ed 1997; 64(7-9):451-8.

26. Hansen $M$, Florescu $A$, Stoltenberg $M$, Podenphant J, Pedersen-Zbinden B, HorslevPetersen K, et al. Bone loss in rheumatoid arthritis. Influence of disease activity, duration of the disease, functional capacity, and corticosteroid treatment. Scand J Rheumatol 1996; 25(6):36776.

27. Hafez EA, Mansour HE, Hamza SH, Moftah SG, Younes TB, Ismail MA. Bone Mineral Density Changes in Patients with Recent-Onset Rheumatoid Arthritis. Clinical Medicine Insights: Arthritis and Musculoskeletal Disorders 2011:4 87 -94 .

28. Heidari B, Jalali F. Bone densitometry in patients with Rheumatoid Arthritis. ActaMedicalranica 2005; 43: 2.

29. Lodder M C, Jong Z, Kostense P J, Molenaar ETH, Staal K, Voskuyl A E, et al. Relation between disease severity and low bone mineral density. Ann Rheum Dis 2004; 63:157680 doi:10.1136/ard.2003.016253

30. Genant H K, Cooper C, Poor G, Reid I, Ehrlich G, Kanis J, et al. Interim report and recommendations of the World Health Organization Task Force for Osteoporosis. Osteoporos Int1999; 10:259-64. 